\title{
Performance evaluation and optimization studies of border irrigation system for wheat in the Indian Punjab
}

\author{
Samanpreet Kaur, Amina Raheja and Rajan Aggarwal \\ Department of Soil and Water Engineering, Punjab Agricultural Engineering, Ludhiana, India
}

\begin{abstract}
Surface irrigation methods are the most widely practiced worldwide for irrigation of row crops. The major problem with these methods is low irrigation efficiency, mainly due to poor design. In the Punjab, border irrigation is used to irrigate wheat crops grown over $90 \%$ of the cultivated area. The evaluation of existing border systems using a surface irrigation model showed that the irrigation conditions, comprising of inflow rate, border dimensions, and cut-off time, were diverse in tubewell and canal irrigated areas. The study also examined the feasibility of optimizing border dimensions taking into consideration the existing irrigation conditions for achieving more than $60 \%$ application efficiency as compared to the $30-40 \%$ achieved under present field conditions. In the case of a border length of $60 \mathrm{~m}$, it was recommended to increase border width in the range of 10-45 m and 20-60 m for different flow rates of 10, 20 and $30 \mathrm{~L} / \mathrm{s}$ in light and medium soils, respectively. For higher flow rates, a border length ranging from 120-150 $\mathrm{m}$ was found to be optimum. For a border length of $150 \mathrm{~m}$, it was recommended to keep a border width ranging from 4-38 m and 8-65 m in light soils and medium soils, respectively, for flow rates of 10, 20, 30 and $60 \mathrm{~L} / \mathrm{s}$. Optimizing border dimensions is a practical way to achieve efficient and judicious use of water resources.
\end{abstract}

Keywords: border irrigation, water management, surface irrigation, application efficiency, Indian Punjab

\section{INTRODUCTION}

The development of the Indian economy is based on agriculture, as this is the main occupation of the people, especially in rural areas. Since independence, many efforts have been made to increase agricultural production to meet the requirements of an ever-increasing population in the country. Land and water are the major resources of agricultural production. About $80-85 \%$ of total water resources are utilized for agriculture. (Kaur, 2011). Identifying the various components of water losses and what improvements can be made is fundamental to the effective use of this resource in agricultural areas (Ting et al., 2009). The significance of irrigation efficiency in agricultural water management has already been emphasized in many earlier studies (Valipour and Montazar 2012a, 2012b, 2012c; Valipour et al., 2013; Valipour et al., 2013a, 2013b; Mahdizadeh Khasraghi et al., 2015).

The state of Punjab is located in the northwest of India. It extends from $29.30^{\circ} \mathrm{N}$ to $32.32^{\circ} \mathrm{N}$ and $73.55^{\circ} \mathrm{E}$ to $76.50^{\circ} \mathrm{E}$. The total area of Punjab is 5.036 million ha and net irrigated area is 4.14 million ha (82.2\%) out of which 2.981 million ha $(72.0 \%)$ is irrigated by tube wells and the remaining area of 1.160 million ha (28.0\%) is irrigated by canals (Brar, 2016). The region is popularly known as the food bowl of India as it contributes $41.5 \%$ of wheat and $24.2 \%$ of rice to the national pool. In this region, surface irrigation covers about $90 \%$ of the total irrigated land. The border method is widely adopted to irrigate field crops like wheat, as it does not need a lot of energy or special equipment. However, the poor design, implementation, and management of surface irrigation systems is generally responsible for inefficient irrigation that seldom exceeds inflow rate. Soil type is generally fixed for a given location, yet to achieve high irrigation performance

\footnotetext{
* To whom all correspondence should be addressed. e-mail: amina19@pau.edu

Received 29 July 2018, accepted in revised form 4 December 2018.
}

system variables such as time of cut-off $\left(t_{c o}\right)$, border length (L) and border width (W) for a given depth of water can be altered. Raine et al. (1997) and Smith et al. (2005) suggested that irrigation application efficiency could be improved to a great extent using a suitable rate of water application and appropriate supply time for specific soil conditions. Although the design of border irrigation systems is quite complicated and needs intensive engineering calculations (Khanjani and Barani, 1999), in recent times many models have been based on 'rule of thumb' of rough empirical guidelines, and approximations. Jurriens et al. (2001) has enabled engineers to systematically improve irrigation system design and operation. Some examples of irrigation models that have been used for design and evaluation purposes include SRFR (Strelkoff et al., 1977); SIRMOD (Walker, 1987) and SURDEV (Jurriens et al., 2001). In Punjab conditions, the border length is fixed for the cropping season and the width can be varied according to crop water requirements. The optimal application efficiency $(E a)$ and minimum runoff fraction $(R f)$ under different field conditions and available flow rate $(Q o)$ may be achieved by varying the time of cut-off $\left(t_{c o}\right)$ and border width $(B)$ for a given depth of water application (Dreq).

In the region, border length and width range between 50-300 $\mathrm{m}$ and 4-60 m, respectively, flow rate ranges from $5 \mathrm{~L} / \mathrm{s}$ to $100 \mathrm{~L} / \mathrm{s}$ and cut-off time varies between 100 and $600 \mathrm{~min}$. Therefore, the present study was planned to (i) analyse the performance of the existing border sizes (ii) optimize the border dimensions and cut-off time under different flow conditions, and (iii) target minimum application depth to achieve maximize application efficiency in Punjab State, India.

\section{MATERIALS AND METHODS}

\section{Study sites}

Two villages, namely Ramgarh in Patiala District (tubewell irrigated) located $30^{\circ} 32^{\prime} \mathrm{N}$ and $76^{\circ} 42.32^{\prime} \mathrm{E}$, and village Bargari (canal command area) located $30^{\circ} 31.26^{\prime} \mathrm{N}$ and $74^{\circ} 57.08^{\prime} \mathrm{E}$ 
in Faridkot District, were selected. The villages were chosen according to water supply conditions for irrigation. The location of the villages is shown in Fig. 1.

There was a typical crop rotation of winter wheat (NovApril) and summer rice (Jun-Oct) in the selected fields. Winter wheat commonly needs 4 to 5 irrigations during its growing season as the precipitation is not sufficient to meet the crop water demand. The depth of each irrigation was kept as $75 \mathrm{~mm}$ which is recommended by the Punjab Agricultural University (Anonymous, 2016) and is widely practiced by the farmers.

\section{Field survey}

The participatory rural appraisal (PRA) survey was conducted to identify the gaps in water management practices. The information on land holdings; soil type; topography; field size; source of irrigation; mode of water conveyance; cropping pattern; land preparation sequence; flow regulation and irrigation scheduling were part of the PRA. Soil samples were also taken from $0-15 \mathrm{~cm}$ depth and analysed using hydrometric method. The volumetric method was used to determine the discharge of the water source. The information on potential problems in irrigation was also collected by interviewing farmers and through written questionnaires as follows:

- Do you do anything for land levelling before sowing?

- Has the availability of irrigation water remained the same in the past 10 years?

- How do you select the method of water application?

- Are you fully satisfied with your method of irrigation?

- Do you think it is necessary to have complete knowledge of method of irrigation, irrigation water measurement and water conveyance?

- Are you sure that you are using irrigation water efficiently?

- How do you ensure that desired amount of water has been applied?

- Do you have an adequate amount of irrigation water available?

- Is the water available when you need it?

- Do irrigation officials interact with the farmers regularly?

\section{SURDEV software}

SURDEV (Jurriens et al., 2001) is a user-friendly computer package for the design, operation and evaluation of surface irrigation systems. The package enables the user to simulate many of the problems involved in the practice of surface irrigation. In addition to simulations, SURDEV performs calculations of the optimal flow rates, field lengths, and cut-off times necessary in surface irrigation situations. The volume balance model (Lewis and Milne, 1938; Hall, 1956; Philip and Farrell, 1964; Wilke and Smerdon, 1965; Hart et al., 1980; Levien and Souza, 1987; Walker and Skogerboe, 1987) consists of a spatially and temporally lumped form of the continuity equation and is applied primarily to the advanced phase.

In this study, soil infiltration properties were based on onedimensional modified Kostiakov equation which assumes that the advance time obeys a power law and infiltration is assumed to be a function of time only. The relationships between cumulative infiltrated depth $(D i)$ and instantaneous infiltration rate $(I)$ with the elapsed time $(T)$ are given by Eqs 1 and 2, respectively:

$$
\begin{aligned}
& D_{i}=k T^{\mathrm{A}}+f_{o} T \\
& I=k A T^{\mathrm{A}-1}+f_{o}
\end{aligned}
$$

The observed field data was used in SURDEV software to evaluate various parameters, viz., application efficiency, storage efficiency, percolation and runoff in existing border sizes. The input parameters included the soil type, required amount of application (Dreq), Manning's roughness coefficient $(n)$, the field slope (So), the intake family ( $k, A$ and $f o$; modified SCS intake families for the Kostiakov equations). The value of Dreq depends on the climatic conditions, crop to be sown, soil conditions and the irrigation scheduling strategy, and in the case of a wheat crop grown under Punjab conditions Dreq was taken as $75 \mathrm{~mm}$. Manning's roughness coefficient $(n)$ is a measure of the resistance effects that flow might encounter as it moves down the border, which is in fact a representation, in somewhat lumped form, of the effects of the roughness of the physical boundaries of the

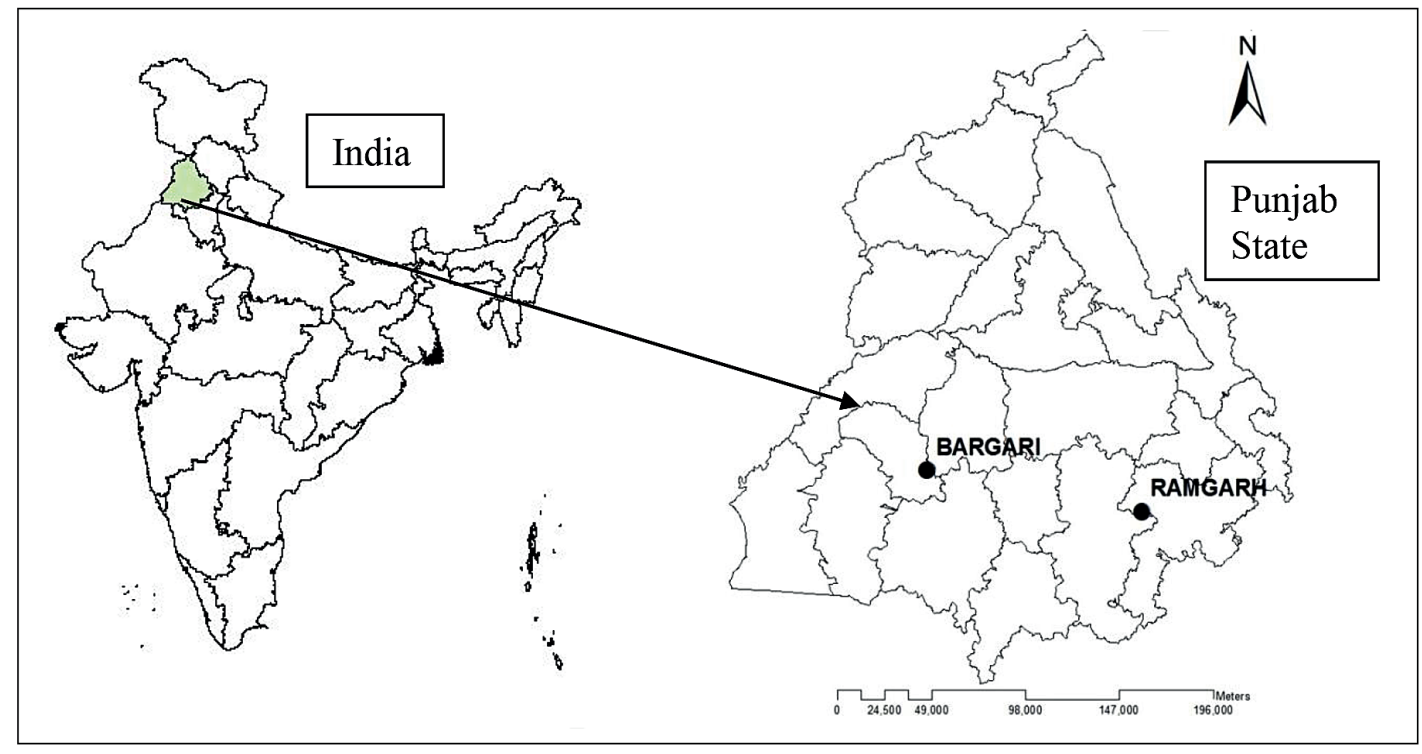

Figure 1

Map showing the locations of villages 
flow and cultivation practices. For small-grained crops under different soils, this value is considered as 0.1 (Jurriens et al., 2001). Based on the field experience, the slopes of $0.5 \%$ and $0.3 \%$ were considered in sandy and loamy soils, respectively (Anonymous, 2017). Average values of other properties, such as bulk density, saturated hydraulic conductivity, were considered from literature (Singh et al., 2009). The infiltration parameters, which are primarily soil dependent, have been selected on the basis of the modified SCS intake families (Walker, 1987) for the modified Kostiakov equations and were taken as 1.0 and 0.6 in sandy soils and loamy soils, respectively. Other parameters (Table 1) were considered for the modified Kostiakov equation.

\section{Optimization of border design}

The parameters (border length, slope, soil and inflow rate, irrigation depth) are generally fixed for a given location; however, to achieve high application and storage efficiency one can alter border width and cut-off time $\left(t_{c o}\right)$. The cut-off time and border width were optimized using SURDEV for border lengths of $60 \mathrm{~m}, 120 \mathrm{~m}$ and $150 \mathrm{~m}$; flow rates of 10,20,30, and $60 \mathrm{~L} / \mathrm{s}$ (which are predominant in field conditions of the State) and two different soil types. The purpose of optimization of these two parameters was to achieve an application efficiency $(E a)$ of more than $60 \%$ and the storage efficiency $(E r)$ such that the minimum infiltrated water depth at the end of the border equals the minimum required water depth (Dreq) and least surface runoff fraction and deep percolation losses, respectively. The sensitivity analysis of border width and cut-off time was done to evaluate which factor was more predominant in the design of a border irrigation system. The sensitivity analysis was done by varying the width by one unit and keeping all the other parameters fixed, and subsequently by varying cutoff time while retaining all other parameters.

\section{RESULTS AND DISCUSSION}

\section{Field evaluation}

The results of the field survey and soil sampling are presented in Table 2. In Ramgarh village, the discharge at the farmer's field varied from 7.4 to $22.3 \mathrm{~L} / \mathrm{s}$, whereas in Bargari village the range was from 50 to $67.8 \mathrm{~L} / \mathrm{s}$. There was considerable variation in the plot sizes adopted by farmers in both the villages.

A length:width ratio of $10-11$ in the canal-irrigated area and of 6-7 in the tubewell-irrigated area was prevalent. In Bargari village, the length (L) of the plot size varied from $62-225 \mathrm{~m}$ and width (B) varied from 9.2-20 $\mathrm{m}$ for the wheat season, whereas in Ramgarh village, the plot length and width ranged between 25-97 $\mathrm{m}$ and 6.3-15 $\mathrm{m}$, respectively.

There was variability in sand, silt and clay percentages in the selected villages. In Bargari village, the average variation ranged from $45-61 \%$ for sand, $23-41 \%$ for silt and $12-18 \%$ for clay, with $50 \%$ farmers having predominantly loam soils, $40 \%$ sandy loam and $10 \%$ other soil types. In Ramgarh village, this ranges from $70-81 \%$ for sand, $13-23 \%$ for silt and $8-14 \%$ for clay, with $50 \%$ of farmers having sandy loam, $39 \%$ loamy sand and $2 \%$ loam soil (Table 2).

The simulation results of border systems under existing field conditions are presented in Table 3. The poor performance of existing irrigation systems is mainly dependent on the combination of present inflow rate, mismatched border dimensions and cut-off time. In the case of the tubewell-irrigated region, where the discharge is less,
TABLE 1

Modified Kostiakov infiltration parameters for different intake families

\begin{tabular}{|l|c|c|c|c|}
\hline $\begin{array}{l}\text { Intake } \\
\text { family }\end{array}$ & $k(\mathrm{~m} / \mathrm{min})$ & $A$ & $f_{0}(\mathrm{~m} / \mathrm{min})$ & Soil type \\
\hline 0.6 & 0.00320 & 0.529 & 0.000136 & $\begin{array}{c}\text { Loam } \\
\text { (medium soils) }\end{array}$ \\
\hline 1.0 & 0.00332 & 0.598 & 0.00212 & $\begin{array}{c}\text { Sand } \\
\text { (light soils) }\end{array}$ \\
\hline
\end{tabular}

\begin{tabular}{|l|l|c|c|l|}
\hline \multicolumn{5}{|c|}{ TABLE 2 } \\
\hline Sr. No. & Farmer ID & $\begin{array}{c}\text { Discharge } \\
(\text { L/s) }\end{array}$ & $\begin{array}{c}\text { Dimension } \\
\text { L } B^{*}(\mathrm{~m})\end{array}$ & Soil type \\
\hline Bargari Village \\
\hline 1 & BF01 & 58.0 & $62 \times 10.5$ & Loam \\
\hline 2 & BF02 & 50.1 & $165 \times 15.0$ & Loam \\
\hline 3 & BF03 & 57.5 & $126 \times 9.2$ & Sandy loam \\
\hline 4 & BF04 & 66.3 & $186 \times 16.0$ & Loam \\
\hline 5 & BF05 & 50.0 & $127.5 \times 12.3$ & Loam \\
\hline 6 & BF06 & 67.8 & $100 \times 30.0$ & Sandy loam \\
\hline 7 & BF07 & 57.6 & $180 \times 18.0$ & Loam \\
\hline Ramgarh Village & & & \\
\hline 1 & RF01 & 21.4 & $71.4 \times 7.4$ & Loamy sand \\
\hline 2 & RF02 & 7.4 & $25.0 \times 6.3$ & Loamy sand \\
\hline 3 & RF03 & 8.8 & $150 \times 8.0$ & Loamy sand \\
\hline 4 & RF04 & 21.2 & $51.2 \times 7.8$ & Loamy sand \\
\hline 5 & RF05 & 36.5 & $51.4 \times 8.2$ & Sandy loam \\
\hline 6 & RF06 & 12.8 & $60.0 \times 12.0$ & Sandy loam \\
\hline 7 & RF07 & 20.1 & $55.7 \times 7.8$ & Loamy sand \\
\hline 8 & RF08 & 22.3 & $55.7 \times 8.5$ & Sandy loam \\
\hline${ }^{*}$ L length and B $=$ breadth & \\
\hline
\end{tabular}

TABLE 3

Evaluation of border system under existing field conditions

\begin{tabular}{|c|c|c|c|c|}
\hline \multirow{2}{*}{$\begin{array}{l}\text { Village } \\
\text { Name of farmer }\end{array}$} & \multicolumn{2}{|c|}{$\begin{array}{l}\text { Ramgarh } \\
\text { (Tube-well } \\
\text { irrigated) }\end{array}$} & \multicolumn{2}{|c|}{$\begin{array}{c}\text { Bargari } \\
\text { (Canal } \\
\text { irrigated) }\end{array}$} \\
\hline & RF03 & RF04 & BF02 & BF03 \\
\hline \multicolumn{5}{|l|}{ Field parameters } \\
\hline Border length $(\mathrm{m})$ & 150 & 60 & 165 & 126 \\
\hline Border width (m) & 8 & 20 & 15 & 9 \\
\hline Flow rate $(\mathrm{L} / \mathrm{s})$ & 8.8 & 21.2 & 50.1 & 57.5 \\
\hline Cut-off time (min) & 480 & 100 & 45 & 120 \\
\hline \multicolumn{5}{|l|}{ Output parameters } \\
\hline $\begin{array}{l}\text { Minimum infiltrated depth } \\
(\mathrm{mm})\end{array}$ & 133 & 51 & 35 & 60 \\
\hline Application efficiency (\%) & 36 & 51 & 70 & 18 \\
\hline Storage efficiency (\%) & 100 & 72 & 51 & 87 \\
\hline Runoff ratio & 29 & 49 & 30 & 82 \\
\hline Average applied depth (mm) & 149 & 54 & 38 & 65 \\
\hline Over-irrigation depth (mm) & 74 & 0 & 0 & 0 \\
\hline Under-irrigation depth (mm) & 0 & 21 & 37 & 10 \\
\hline Over-irrigation length (m) & 150 & 0 & 0 & 0 \\
\hline
\end{tabular}



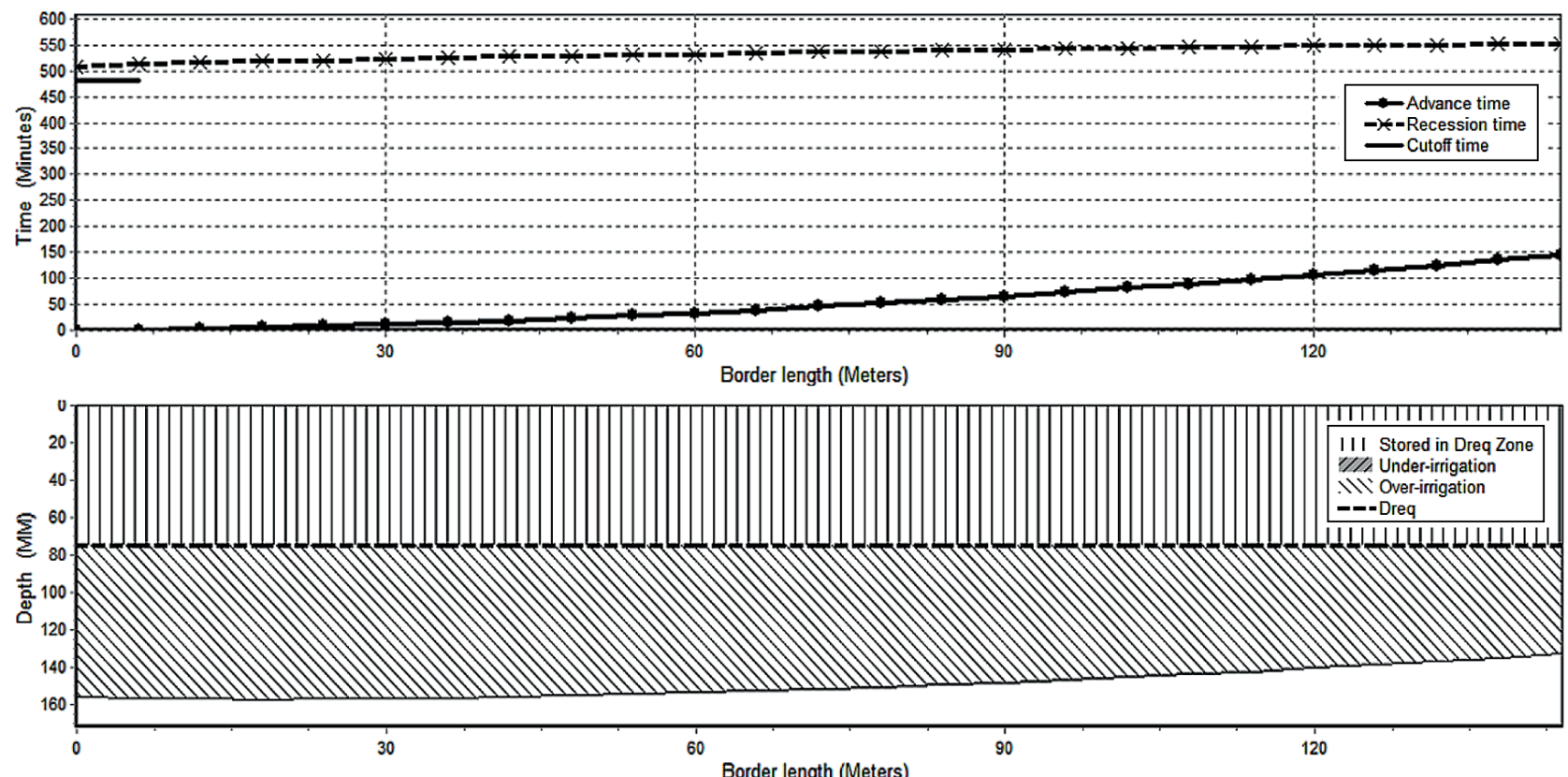

Figure 2

Advance curve and recession curve at farmer's field (RFO3)
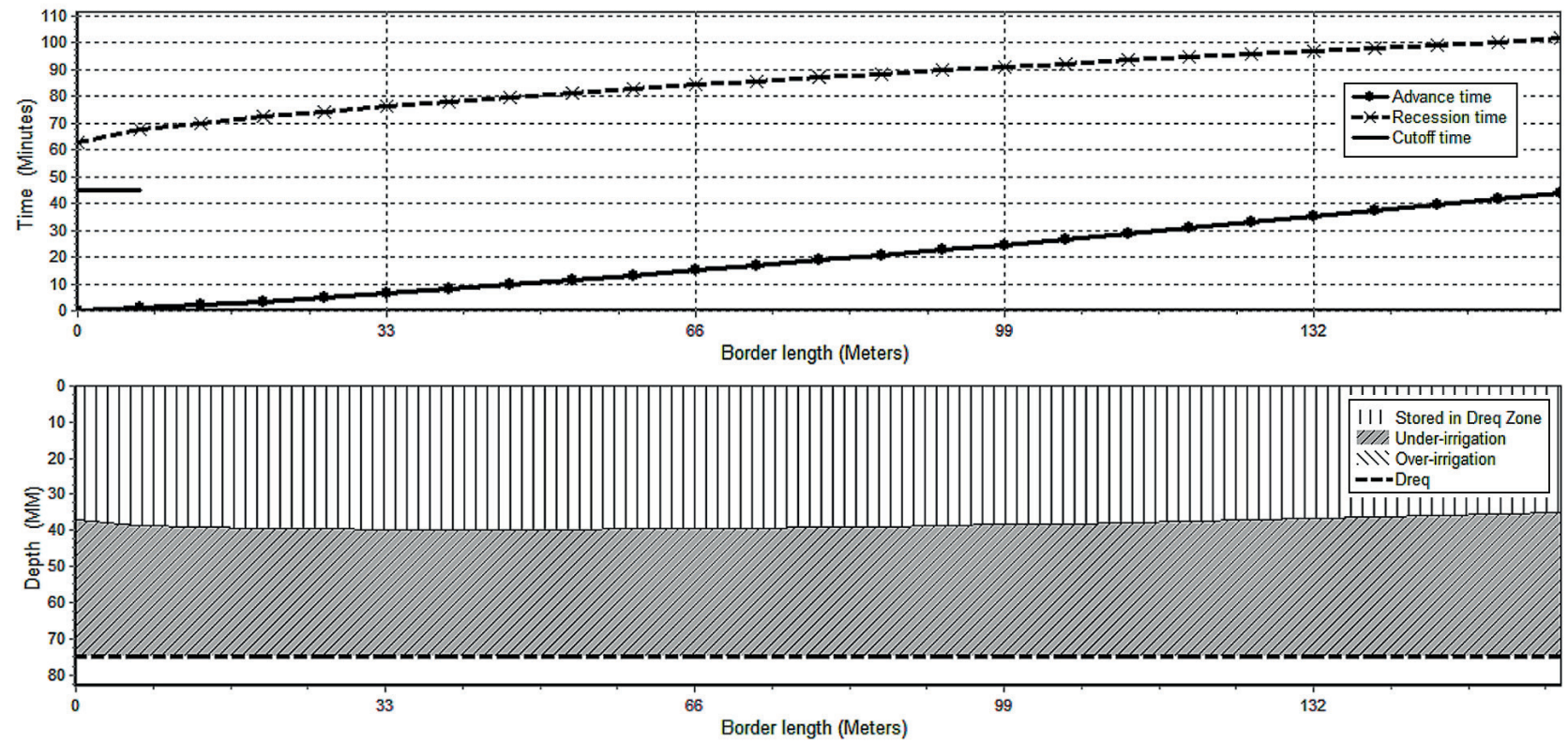

Figure 3

Advance curve and recession curve at farmer's field (BF 02)

farmers often keep the tubewell on for 7-8 $\mathrm{h}$ for filling of one plot which results in over-irrigation of the entire length of field, as shown in Fig. 2. The water infiltration distribution profiles are non-uniform along the length of borders.

Although the farmer is able to attain more than $100 \%$ storage efficiency with average irrigation depth of $149 \mathrm{~mm}$, against a required depth of $75 \mathrm{~mm}$, this results in a low application efficiency of $36 \%$. However, in the case of a tubewell-irrigated area with medium discharge and cut-off time of 1.5-2 h, better application efficiency was achieved but the storage efficiency was less than required (Table 3).
In the case of the canal-irrigated area, the farmer gets their water supply at their turn, depending upon the cropped area. Although the discharge is high, the farmer has limited awareness about the relevant plot size and appropriate cutoff time. Table 3 presents two cases of canal irrigation with application efficiency varying between 18 and $70 \%$. In both cases under-irrigation at depths of $37 \mathrm{~mm}$ and $10 \mathrm{~mm}$ were observed (Fig. 3), relative to the required depth of $75 \mathrm{~mm}$, due to short cut-off times and variation in plot sizes. 


\section{Evaluation of border optimization of border design}

The design of a border irrigation system considers the flow to be non-linear. Therefore, the border width does not vary proportionally with flow rate and border length. The range of border width, cut-off time, deep percolation ratio and runoff fraction for different border lengths, flow rates, and soil types is presented in Tables 4 and 5, respectively. The range was obtained to achieve an application efficiency of more than $60 \%$ and required depth of irrigation throughout the border length The optimum design parameters are highlighted in grey for different border lengths and flow rate in Tables 4 and 5 .

For a given border length, the border width was found to be more affected by soil type, with a minimum in light and maximum in medium soils, irrespective of the flow rate.
A comparison of existing farm conditions (Table 2) with simulated results (Table 3 ) shows that performance efficiency can be improved by adopting recommended cut-off time and width. Considering the case of farmer RF03, with length $150 \mathrm{~m}$; width $8 \mathrm{~m}$; flow rate $8.8 \mathrm{~L} / \mathrm{s}$; and $t_{c o}$ of 480 min yielded an $E a$ of $36 \%$ which can be improved to $64 \%$ by decreasing width to $6 \mathrm{~m}$ and cut-off time to $176 \mathrm{~min}$. Similarly, for Farmer BF03 (Table 2), the application efficiency can be enhanced from $18 \%$ to $66 \%$ by increasing the width from $9 \mathrm{~m}$ to $35 \mathrm{~m}$.

In the case of small plot size, as the flow rate increases, the application efficiency decreases and surface runoff increases. It is suggested that for a border length of $60 \mathrm{~m}$, border width should be kept in the range of 10-45 $\mathrm{m}$ and $20-60 \mathrm{~m}$ for flow rates of 10, 20 and $30 \mathrm{~L} / \mathrm{s}$ in sandy and loamy soils, respectively. Therefore, at higher flow rates border length

\begin{tabular}{|c|c|c|c|c|c|}
\hline \multicolumn{6}{|c|}{$\begin{array}{l}\text { TABLE } 4 \\
\text { Evaluation of border irrigation parameters in light soils for } 75 \mathrm{~mm} \text { depth of irrigation }\end{array}$} \\
\hline Flow rate (L/s) & Width (m) & $\begin{array}{l}\text { Cut-off time } \\
\text { (min) }\end{array}$ & $\begin{array}{l}\text { Application } \\
\text { efficiency (\%) }\end{array}$ & $\begin{array}{l}\text { Deep percolation } \\
\quad \text { ratio }(\%)\end{array}$ & $\begin{array}{c}\text { Runoff } \\
(\%)\end{array}$ \\
\hline \multicolumn{6}{|c|}{ Length $=60 \mathrm{~m}$} \\
\hline 10 & 10 & $122-124$ & 63 & $9-10$ & $29-30$ \\
\hline 10 & 14 & $157-176$ & 67 & $20-25$ & $13-15$ \\
\hline 10 & 16 & $187-201$ & 64 & $28-32$ & $8-9$ \\
\hline 20 & 20 & $119-126$ & 62 & $8-10$ & $29-30$ \\
\hline 20 & 24 & $135-151$ & 66 & $13-18$ & $20-22$ \\
\hline 20 & 28 & $157-60$ & 67 & $20-25$ & $13-15$ \\
\hline 20 & 30 & $170-189$ & 66 & $24-29$ & $10-12$ \\
\hline 30 & 35 & $133-146$ & 65 & $13-15$ & $21-23$ \\
\hline 30 & 40 & $149-168$ & 67 & $16-18$ & $15-23$ \\
\hline 30 & 45 & $172-189$ & 66 & $10-12$ & $25-29$ \\
\hline \multicolumn{6}{|c|}{ Length $=120 \mathrm{~m}$} \\
\hline 20 & 10 & $119-126$ & 63 & $10-12$ & $27-28$ \\
\hline 20 & 15 & 174-189 & 64 & $26-30$ & $9-10$ \\
\hline 30 & 15 & 119-126 & 63 & $10-12$ & $27-28$ \\
\hline 30 & 20 & $151-168$ & 66 & $12-20$ & $14-16$ \\
\hline 30 & 25 & $204-210$ & 61 & $33-34$ & $6-7$ \\
\hline 60 & 30 & $119-126$ & 63 & $10-12$ & $27-28$ \\
\hline 60 & 35 & $133-147$ & 66 & $15-19$ & $20-22$ \\
\hline 60 & 48 & 191-201 & 63 & $30-32$ & $7-8$ \\
\hline \multicolumn{6}{|c|}{ Length $=150 \mathrm{~m}$} \\
\hline 10 & 4 & $118-125$ & 63 & $26-27$ & $11-13$ \\
\hline 10 & 6 & $176-186$ & 64 & $27-30$ & $9-10$ \\
\hline 20 & 7 & 109-110 & 61 & $32-33$ & $8-9$ \\
\hline 20 & 10 & $142-157$ & 66 & $18-22$ & $16-18$ \\
\hline 20 & 13 & 198-204 & 62 & $32-33$ & $6-7$ \\
\hline 30 & 11 & $112-115$ & 61 & $9-10$ & $30-31$ \\
\hline 30 & 15 & $142-157$ & 66 & $18-22$ & $16-18$ \\
\hline 30 & 20 & $206-210$ & 61 & $34-35$ & $6-7$ \\
\hline 60 & 21 & $108-110$ & 61 & $8-9$ & $32-33$ \\
\hline 60 & 35 & 169-183 & 65 & $26-29$ & $9-10$ \\
\hline 60 & 40 & $206-210$ & 61 & $34-35$ & $5-6$ \\
\hline
\end{tabular}




\begin{tabular}{|c|c|c|c|c|c|}
\hline \multicolumn{6}{|c|}{$\begin{array}{c}\text { TABLE } 5 \\
\text { Evaluation of border irrigation parameters in medium soils for } 75 \mathrm{~mm} \text { depth of irrigation }\end{array}$} \\
\hline Flow rate (L/s) & Width (m) & $\begin{array}{c}\text { Cut-off } \\
\text { time (min) }\end{array}$ & $\begin{array}{c}\text { Application } \\
\text { efficiency (\%) }\end{array}$ & $\begin{array}{l}\text { Deep percolation } \\
\text { ratio (\%) }\end{array}$ & Runoff \\
\hline \multicolumn{6}{|c|}{ Length $=60 \mathrm{~m}$} \\
\hline 10 & 20 & $233-252$ & 64 & $11-14$ & $25-26$ \\
\hline 10 & 24 & $270-302$ & 67 & $17-22$ & $16-18$ \\
\hline 10 & 32 & $396-403$ & 61 & $34-35$ & $5-6$ \\
\hline 20 & 34 & 211 & 60 & 33 & 7 \\
\hline 20 & 40 & $233-251$ & 64 & $11-14$ & $25-26$ \\
\hline 20 & 50 & $282-315$ & 67 & $19-24$ & $14-16$ \\
\hline 30 & 50 & 209 & 60 & 7 & 34 \\
\hline 30 & 60 & $233-252$ & 64 & $11-14$ & $25-26$ \\
\hline \multicolumn{6}{|c|}{ Length $=120 \mathrm{~m}$} \\
\hline 10 & 10 & $232-252$ & 65 & $12-16$ & $23-25$ \\
\hline 10 & 16 & 403 & 60 & 36 & 5 \\
\hline 20 & 18 & $216-226$ & 62 & $9-11$ & $28-29$ \\
\hline 20 & 22 & $251-276$ & 66 & $16-19$ & $19-21$ \\
\hline 20 & 32 & 403 & 60 & 36 & 5 \\
\hline 30 & 25 & 207 & 60 & 8 & 32 \\
\hline 30 & 35 & $265-294$ & 66 & $18-22$ & $16-18$ \\
\hline 30 & 40 & $307-335$ & 65 & $24-28$ & $11-12$ \\
\hline 60 & 50 & 207 & 60 & 8 & 32 \\
\hline 60 & 55 & $219-230$ & 63 & $10-12$ & $27-28$ \\
\hline 60 & 60 & $232-252$ & 65 & $12-16$ & $23-25$ \\
\hline \multicolumn{6}{|c|}{ Length $=150 \mathrm{~m}$} \\
\hline 10 & 8 & $232-252$ & 65 & $13-16$ & $22-24$ \\
\hline 10 & 12 & $365-378$ & 62 & $32-33$ & $6-7$ \\
\hline 20 & 18 & $256-283$ & 66 & $17-21$ & $17-19$ \\
\hline 20 & 25 & 390 & 60 & 35 & 5 \\
\hline 30 & 20 & $205-210$ & 61 & $8-9$ & $31-32$ \\
\hline 30 & 25 & $240-262$ & 65 & $14-18$ & $21-23$ \\
\hline 30 & 38 & 399 & 60 & 35 & 5 \\
\hline 60 & 40 & $205-210$ & 61 & $8-9$ & $31-32$ \\
\hline 60 & 55 & $261-288$ & 66 & $18-22$ & $16-19$ \\
\hline 60 & 75 & 390 & 60 & 35 & 5 \\
\hline
\end{tabular}

greater than $120 \mathrm{~m}$ should be adopted. For higher flow rates, a border length ranging from $120-150 \mathrm{~m}$ is found to be optimum. In the case of a fixed border length of $150 \mathrm{~m}$, it is recommended to keep border width ranging from $4-40 \mathrm{~m}$ and $8-75 \mathrm{~m}$ in light soils and medium soils, respectively, for different flow rates of $10,20,30$ and $60 \mathrm{~L} / \mathrm{s}$ (Table 5). In case the flow rate increases from $10 \mathrm{~L} / \mathrm{s}$ to $20 \mathrm{~L} / \mathrm{s}$, the width should also be doubled for different border lengths.

The cut-off time was largely affected by soil type and it is recommended that it vary between 119-210 min and 209-403 min in sandy and loam soils, respectively, for different flow rates and border lengths. Also, the allowable cut-off time ranges within $10-12 \%$ of the optimum cut-off time in the case of light soils and within $8-10 \%$ in medium soils, for optimum border width and different border lengths.
In light soils having a length of $150 \mathrm{~m}$, if flow rate is known, the optimum application efficiency can be achieved by keeping the width at numerically half of the flow rate value, whereas in medium soils, this value was numerically equal to flow rate. At higher border lengths, cut-off time is be numerically equal to flow rate.

The sensitivity analysis showed that the application efficiency was sensitive to border width at low discharges and the decrease was more evident for longer borders. Also, the variation in efficiency was more prominent in light soils as compared to medium soils. It was also observed that at higher border lengths, cut-off time was insensitive to different flow rates and border widths. 


\section{CONCLUSIONS AND RECOMMENDATIONS}

The groundwater depletion in Punjab State is at critical levels and the government is introducing many initiatives to address this problem. A practical and water-saving irrigation system is urgently required to relieve the lack of water resources in northern India. For this purpose, the potential of improving border irrigation performance through border dimension optimization was evaluated using a simulation model. Field studies indicate poor performance of current irrigation systems due to mismatched irrigation system conditions, for example, supply discharge, border dimensions, and relatively long cut-off distances. In this study, the effect of changes in border width and cut-off time for a desired depth of application and application efficiency of more than $60 \%$ under existing field conditions (flow rate, border length, slope and soil conditions) was evaluated. The simulated design shows that it is possible to select a suitable combination of the border system's parameters (border length, inflow rate, and cut-off time) to obtain an application efficiency of more than $60 \%$ compared to the existing efficiency of $30-40 \%$. For efficient irrigation when the border width increases, the border length should be shortened. The coarser the soil, the shorter the field and the steeper the field slope, the more pronounced are the variations of the performance indices versus changes in inflow rate, border length and cut-off time. The results present a broad guideline for improving existing on-farm irrigation systems for better management of the scarce resources of agricultural production. However, this does not consider spatial and temporal variability in the parameters. Taking into account the case study area of the Punjab region, where wheat is grown over an area of 3600000 hectare having an average irrigation requirement of $400 \mathrm{~mm}$. Optimizing border dimensions can save approximately 12 billion $\mathrm{m}^{3} / \mathrm{yr}$ water for this wheat crop. Thus, it is sensible to persuade farmers to establish standard border dimensions for water saving farming practices in Punjab.

\section{REFERENCES}

ANONYMOUS (2017) Package of practices for rabi crops. Punjab Agricultural University. Ludhiana. $164 \mathrm{pp}$.

BRAR MS, AGGARWAL R and KAUR S (2016) GISbased investigations on ground water behavior in Indian Punjab. Agric. Res. J. 53 (4) 519-523. https://doi. org/10.5958/2395-146X.2016.00103.4

HALL WA (1956) Estimating irrigation border flow. Agric. Eng. 37 (4) 263-265.

HART WE, COLLINS HG, WOODWARD G and HUMPHERYS AS (1980) Design and operation of gravity or surface irrigation systems. In: Jensen ME (ed.) Design and Operation of Farm Irrigation Systems. American Society of Agricultural Engineers, Michigan.

JURRIËNS M, ZERIHUN D, BOONSTRA J and FEYEN J (2001) SURDEV: Surface Irrigation Software. ILRI Publication 59. ILRI, Wageningen.
KAUR B (2011) Impact of climate change and cropping pattern on ground water resources of Punjab. Indian J. Agric. Econ. 66 (3) 373-387.

KHANJANI MJ and BARANI GA (1999) Optimum design of border irrigation system. Am. Water Resour. Assoc. 35 (4) 787-792. https:// doi.org/10.1111/j.1752-1688.1999.tb04174.x

LEVIEN SLA and SOUZA F (1987) Algebraic computation of flow in furrow irrigation. J. Irrig. Drain. Eng. 113 (3) 367-377. https://doi. org/10.1061/(ASCE)0733-9437(1987)113:3(367)

LEWIS MR and MILNE WEL (1938) Analysis of border irrigation. Agric. Eng. 19 267-272.

MAHDIZADEH KHASRAGHI M, GHOLAMI SEFIDKOUHI MA and VALIPOUR M (2015) Simulation of open and closed-end border irrigation systems using SIRMOD. Arch. Agron. Soil Sci. 61 (7) 929-941. https://doi.org/10.1080/03650340.2014.981163

PHILIP JR and FARRELL SA (1964) General solution of the infiltration-advance problem in irrigation hydraulics. J. Geophys. Res. 69 (4) 621-631. https://doi.org/10.1029/JZ069i004p00621

RAINE SR, MCCLYMONT DJ and SMITH RJ (1997) The development of guidelines for surface irrigation in areas with variable infiltration. Australian Society of Sugar Cane Technologists, Cairns, Australia. 293-301.

SINGH K B, JALOTA SK and SHARMA BD (2009) Effect of continuous rice-wheat rotation on soil properties from four agro-ecosystems of Indian Punjab. Comm. Soil Sci. Plant Anal. 40 (17-18) 2945-2958. https://doi.org/10.1080/00103620903221225

SMITH RJ, RAINE SR and MINKEVICH J (2005) Irrigation application efficiency and deep drainage potential under surface irrigated cotton. Agric. Water Manage. 71 (2) 117-130. https://doi. org/10.1016/j.agwat.2004.07.008

STRELKOFF T and KATOPODES ND (1977) Border irrigation hydraulics with zero-inertia. J. Irrig. Drain. Div. 103 (3) 325-342.

VALIPOUR M (2013a) Necessity of irrigated and rainfed agriculture in the world. Irrig. Drain. Syst. Eng. S9 e001. URL: http://omicsgroup. org/journals/necessity-of-irrigated-and-rainfed-agriculturein-theworld-2168-9768.S9-e001.php?aid=12800

VALIPOUR M (2013b) Evolution of irrigation-equipped areas as share of cultivated areas. Irrig. Drain. Sys. Eng. 2 e114. https://doi. org/10.4172/2168-9768.1000e114

VALIPOUR M, BANIHABIB ME and BEHBAHANI SMR (2013) Comparison of the ARMA, ARIMA, and the autoregressive artificial neural network models in forecasting the monthly inflow of Dez dam reservoir. J. Hydrol. 476 433-441. https://doi. org/10.1016/j.jhydrol.2012.11.017

VALIPOUR M and MONTAZAR AA (2012a) Optimize of all effective infiltration parameters in furrow irrigation using visual basic and genetic algorithm programming. Aust. J. Basic Appl. Sci. 6 132-137.

VALIPOUR M and MONTAZAR AA (2012b) Sensitive analysis of optimized infiltration parameters in SWDC model. Adv. Environ. Biol. 6 2574-2581.

VALIPOUR M and MONTAZAR AA (2012c) An evaluation of SWDC and WINSRFR models to optimize of infiltration parameters in furrow irrigation. Am. J. Sci. Res. 69 128-142.

WALKER WR and SKOGERBOE GV (1987) Surface Irrigation: Theory and Practice. Prentice-Hall, Englewood Cliffs, NJ, USA.

WILKE OC and SEMERDON ET (1965) A solution of the irrigation advance problem. J. Irrig. Drain. Div. 91 (3) 23-34.

TING KC, FLEISHER DH and RODRIGUEZ LF (2009) Systems Analysis and Modeling in Food and Agriculture. EOLSS Publishers Co., Oxford. 488 pp. 